\title{
Proximate, functional, anti nutrient and antimicrobial properties of avocado pear (Persea americana) seeds
}

\begin{abstract}
The proximate, functional, antinutrient and antimicrobial properties of avocado pear (Persea americana) seeds were studied using standard methods. The proximate contents (\%) of avocado peat seed flour, ASF, in decreasing order were moisture (13.09 \pm 0.14$)$ followed by ash $(3.82 \pm 0.00)$, fibre $(2.87 \pm 0.00)$, protein $(2.64 \pm 0.01)$ and fat $(0.33 \pm 0.00)$. The energy value, carbohydrate and dry matter content respectively was $334.01 \pm 1.05 \%, 80.12 \pm 0.15 \%$ and $86.91 \pm 0.14 \%$ while the water absorption capacity and oil absorption capacity respectively was $2.70 \pm 0.00 \%$ and $1.80 \pm 0.00 \%$. The anti-nutrients $(\mathrm{mg} / 100 \mathrm{~g})$ in decreasing order were saponins $(8.10 \pm 0.01)$ followed by alkaloids $(2.14 \pm 0.00)$, flavonoids $(1.81 \pm 0.01)$, tannins $(1.14 \pm 0.01)$, cyanogenic glycosides $(1.02 \pm 0.00)$ and phenols $(0.29 \pm 0.01)$. The avocado pear seed extract (ASE) elicited antibacterial activity $(\mathrm{mm})$ against Proteus mirabilis (23 \pm 0.14$)$, Staphylococcus aureus (16 \pm 0.04$)$ and Pseudomonas aeruginosa $(15 \pm 0.11)$ though lower than the corresponding activity by the standard, Ciprofloxacin. ASE had higher activity $(18 \pm 0.31 \mathrm{~mm})$ against the fungus, Aspergilus niger compared with the standard antifungal, Ketoconazole $(8 \pm 0.22 \mathrm{~mm})$ while it had a comparable activity as the standard against Candida albicans but no activity against Penicillum notatum in contrast to the standard drug $(6 \pm 0.24 \mathrm{~mm})$. Thus, ASF had appreciable nutrient and antinutrient contents with apparently moderate storage value while, out of the tested pathogens, ASE had a broad spectrum antibacterial activity, a selective antifungal activity and an overriding activity against Aspergilus niger. These while highlighting possible diet and drug potentials of ASF and ASE, respectively, provided basis for ethno-medicinal applications of avocado pear seeds, hence warranting further studies.
\end{abstract}

Keywords: pathogens, anti-nutrients, antimicrobial, Aspergilus niger, Proteus mirabilis
Volume 8 Issue I - 2018

\author{
Anthony Cemaluk C Egbuonu, Immaculate \\ C Opara, Chimaraoke Onyeabo, Nancy $O$ \\ Uchenna \\ Department of Biochemistry, Michael Okpara University of \\ Agriculture Umudike, Nigeria
}

Correspondence: Anthony Cemaluk C Egbuonu, Department of Biochemistry, Michael Okpara University of Agriculture Umudike, Nigeria, Tel +23480 3636 6565, Email tonycemalukegbuonu@yahoo.com, egbuonu.anthony@mouau.edu.ng

Received: October 22, 2017 | Published: February 15, 2018
Abbreviations: ASF, avocado pear seed flour; ASE, ethanolic extract of avocado pear seed flour; OAC, oil absorption capacity; WAC, water absorption capacity; AOAC, association of analytical chemists; MHA, mueller hinton agar; ANOVA, analysis of variance; $\mathrm{SD}$, standard deviation

\section{Introduction}

Generally, plant parts (seeds, leaves, bark, fruits and stems) contain bioactive agents. These confer such plant parts with nutritive and antimicrobial properties which could contribute to the management of diseases. ${ }^{1-6}$ However, proper assessment on the possible dietary and therapeutic potentials of such plant parts are required for informed use in animals, including human.

Avocado plant (Persea americana), a plant belonging to the family of Lauraceae and genus, persea bears fruit known as avocado pear or alligator pear that contains the avocado pear seed. Reported uses of avocado pear seed include use in the management of hypertension, diabetes, cancer and inflammation. ${ }^{7-9}$ The fruit is known as $u b e$ oyibo (loosely translated to 'foreign pear') in Ojoto and neighboring Igbo speaking communities south east Nigeria. ${ }^{10}$ Different parts of avocado pear were used in traditional medications for various purposes including as an antimicrobial. ${ }^{11,12}$ That notwithstanding, the avocado pear seeds are essentially discarded as agro-food wastes hence underutilized. Exploring the possible dietary and therapeutic potentials of especially underutilized agro-food wastes will in addition reduce the possible environmental waste burden. ${ }^{13-15}$ Thus, this study was warranted and aimed at assessing the proximate, functional, anti-nutrients and antimicrobial properties of avocado pear seed to provide basis for its possible dietary use and justification for its ethno-medicinal use. The objectives set to achieving the study aim as stated were by determining the proximate, functional, antinutrient and antimicrobial properties of avocado pear (Persea americana) seeds using standard methods as in the study design.

\section{Materials and methods}

\section{Collection, identification, preparation and extraction of plant materials}

Avocado pear fruits were bought in a local market in Umuahia during the fruiting season (June, 2015). The fruits were identified as that of Persea americana mill (Lauraceae) in the Plant Science department of Michael Okpara University of Agriculture Umudike, Abia State, Nigeria. The fruits were deseeded by removing the fleshy cover. The resultant seeds were washed with clean tap water, crushed into smaller pieces with the help of manual grater and sun-dried for three days. The sun-dried seeds were subsequently milled into powder using a laboratory miller (ED-5, U.S.A) and shared into two. 
One part of the avocado pear seed flour, ASF, was stored in an air tight container until used for the determination of proximate, functional and anti-nutrient contents. The other part was extracted by cold maceration method using ethanol as the extracting solvent. The extraction method involved weighing $700 \mathrm{~g}$ of the avocado pear seed flour into a volumetric flask, soaking the weighed ASF in $1400 \mathrm{ml}$ of $90 \%$ ethanol with intermittent shaking and stirring for three days and thereafter filtering with No 1 What mann filter paper. The filtrate was concentrated using water bath at $60^{\circ} \mathrm{C}$ and was further dried in an oven at $50^{\circ} \mathrm{C}$. The resultant avocado pear seed extract (ASE) was placed in a sample bottle and stored in a refrigerator until used in determining the antimicrobial (antibacterial and antifungal) activity of selected pathogens.

\section{Determination of studied parameters}

The proximate contents (dry matter, moisture, protein, ash, crude fibre and fat) of ASF were determined according to corresponding method of Association of Analytical Chemists (AOAC, 1990). From the determined proximate contents, carbohydrate content and energy value of ASF were respectively calculated by difference thus:

Carbohydrate $(\%)=100-($ protein $+\mathrm{ash}+\mathrm{fat}+$ moisture content $) \%$.

Energy value $(\%)=(\%$ carbohydrate $\times 4)+(\%$ protein $\times 4)+(\%$ fat $\times 9)$.

The functional properties (water absorption capacity, WAC and oil absorption capacity, OAC) were determined as the weight of water or oil absorbed and held by $1 \mathrm{~g}$ of the sample. ${ }^{16}$ Alkaloids content was determined by the method of Harbone ${ }^{17}$ as described by Okwu $\&$ Morah ${ }^{18}$ while saponins content was determined by the method as described earlier. ${ }^{18,19}$ Tannins content was determined by Folin-Dennis colorimetric method as described by Pearson ${ }^{20}$ and reported earlier. ${ }^{21}$ Phenols content in the flour sample was determined by the method in Association of Analytical Chemists, AOAC, ${ }^{22}$ while cyanogenic glycosides content was determined using the method described by Onwuka $^{23}$ whereas flavonoids content was determined by the method described by Okwu \& Omodamiro. ${ }^{24}$

The determination of antimicrobial activity of avocado pear seeds flour extract(ASE) against six clinical isolates comprising three bacteria (Pseudomonas aeruginosa, Proteus mirabilis and Staphylococcus aureus) and three fungi (Aspergulus niger, Canidida albican and Penicillum notatum) obtained from Federal Medical Centre Umuahia, Abia State, Nigeria was according to the disc diffusion method. ${ }^{25}$ In brief, discs (6mm in diameter) were made from Whatman No.1 grade filter paper with the aid of a mechanical perforator and sterilized by autoclaving at $0^{\circ} \mathrm{C}$. The blank sterile discs were placed on the inoculated Mueller Hinton Agar (MHA) surface and impregnated with $20 \mu \mathrm{l}$ of stock solution $(2000 \mu \mathrm{g} / \mathrm{disc})$. Ciprofloxacin and Ketoconazole were respectively used as antibacterial and antifungal controls. The plates were incubated at $37^{\circ} \mathrm{C}$ for 24 hours. All tests were performed in triplicate and the antimicrobial activity was expressed as the mean diameter of inhibition zones $(\mathrm{mm})$ produced by the plant extract.

\section{Statistical analysis}

Descriptive statistics and test for significant difference in mean of the generated data were carried out by analysis of variance (ANOVA) using the statistical package for social sciences for Windows version 16. The turkey post hoc test was used to identify the means that differ significantly at $\mathrm{p}<0.05$. Results were expressed as mean \pm standard deviation, SD of duplicate for proximate, functional and anti-nutrient properties) or triplicate (for antimicrobial property) determinations.

\section{Results and discussion}

\section{Results}

As shown on Table 1, the proximate contents (\%) of avocado peat seed flour, ASF, were in the order: moisture $(13.09 \pm 0.14)>$ ash $(3.82 \pm 0.00)>$ fibre $(2.87 \pm 0.00)>$ protein $(2.64 \pm 0.01)>$, fat $(0.33 \pm 0.00)$. The energy value, carbohydrate and dry matter content respectively were $334.01 \pm 1.05 \%, 80.12 \pm 0.15 \%$ and $86.91 \pm 0.14 \%$. Out of the determined functional properties, the water absorption capacity $(2.70 \pm 0.00 \%)$ was higher than the oil absorption capacity $(1.80 \pm 0.00 \%)$.

Table I Proximate and some functional properties of avocado pear seeds

\begin{tabular}{ll}
\hline Parameters & Concentration (\%) \\
\hline Moisture Content & $13.09 \pm 0.14$ \\
Dry Matter & $86.91 \pm 0.14$ \\
Crude Protein & $2.64 \pm 0.01$ \\
Ash & $3.82 \pm 0.00$ \\
Crude Fat/Lipid & $0.33 \pm 0.00$ \\
Crude Fibre & $2.87 \pm 0.00$ \\
Carbohydrate & $80.12 \pm 0.15$ \\
Energy Value & $334.01 \pm 1.05$ \\
Water Absorption Capacity & $2.70 \pm 0.00$ \\
Oil Absorption Capacity & $1.80 \pm 0.00$ \\
\hline
\end{tabular}

Values are means \pm standard deviations of duplicate determinations

The anti-nutrients $(\mathrm{mg} / 100 \mathrm{~g})$ as shown on Table 2 were in the order: saponins $(8.10 \pm 0.01)>$ alkaloids $(2.14 \pm 0.00)>$ flavonoids $(1.81 \pm 0.01)>$ tannins $(1.14 \pm 0.01)>$ cyanogenic glycosides $(1.02 \pm 0.00)>$ phenols $(0.29 \pm 0.01)$.

Table 2 Anti-nutrients composition of ethanolic extract of avocado pear seeds

\begin{tabular}{ll}
\hline Anti-nutrients & Concentration $(\mathbf{m g} / \mathbf{l 0 0 g})$ \\
\hline Alkaloids & $2.14 \pm 0.00$ \\
Saponins & $8.10 \pm 0.01$ \\
Tannins & $1.14 \pm 0.01$ \\
Flavonoids & $1.81 \pm 0.01$ \\
Cyanogenic Glycosides & $1.02 \pm 0.00$ \\
Phenols & $0.29 \pm 0.01$
\end{tabular}

Values are means \pm standard deviations of duplicate determinations

As depicted on Table 3, the avocado pear seed extract (ASE) elicited antibacterial activity $(\mathrm{mm})$ against $P$. mirabilis $(23 \pm 0.14)$ which was higher than that against $S$. aureus $(16 \pm 0.04)$ followed by that against $P$. aeruginosa $(15 \pm 0.11)$. The activity of ASE against these pathogens was however lower than the corresponding activity elicited by the standard drug, Ciprofloxacin (Disc diffusion pictures not provided). 
Table 3 Antibacterial activity of ethanolic extract of avocado pear seeds and standard antibacterial, Ciprofloxacin, against $P$. aeruginosa, $P$. mirabilis and S. aureus

\begin{tabular}{lll}
\hline \multirow{2}{*}{ Organisms } & \multicolumn{2}{l}{ Diameter of zone of inhibition $(\mathbf{m m})$} \\
\cline { 2 - 3 } & Extract & Ciprofloxacin \\
\hline Pseudomonas aeruginosa & $15 \pm 0.11$ & $41 \pm 0.02$ \\
Proteus mirabilis & $23 \pm 0.14$ & $33 \pm 0.13$ \\
Staphylococcus aureus & $16 \pm 0.04$ & $45 \pm 0.06$ \\
\hline
\end{tabular}

Values are means \pm standard deviations of triplicate determinations

The sample extract, ASE, had higher activity, mm, (18 \pm 0.31$)$ against the fungus, Aspergilus niger when compared with the standard drug, Ketoconazole ( $8 \pm 0.22)$. And, the activity of ASE against Candida albicans was comparable with that of Ketoconazole $(32 \pm 0.14)$, a standard antifungal. However, the extract elicited no activity against the pathogenic fungus, Penicillum notatum in contrast to the standard drug $(6 \pm 0.24)$ (Table 4$)$.

Table 4 Antifungal activity of ethanolic extract of avocado pear seeds and standard antifungal, Ketoconazole, against A. niger, C. albican and P. notatum

\begin{tabular}{lll}
\hline \multirow{2}{*}{ Organisms } & \multicolumn{2}{l}{ Diameter of Zone of Inhibition $(\mathbf{m m})$} \\
\cline { 2 - 3 } & Extract & Ketoconazole \\
\hline Aspergilus niger & $18 \pm 0.31$ & $8 \pm 0.22$ \\
Candida albican & $32 \pm 0.14$ & $48 \pm 0.11$ \\
Penicillum notatum & 0 & $6 \pm 0.24$ \\
\hline
\end{tabular}

Values are means \pm standard deviations of triplicate determinations

\section{Discussion}

The proximate profile of the ASF (Table 1) showed higher moisture content compared to the others suggesting poor storability of the avocado pear seed flour. However, while this compared with the value $(9.92 \pm 0.01 \%)$ reported by Arukwe et al. ${ }^{26}$ the value was much lower than the range (54-65.62\%) reported by Oluwole et al., ${ }^{27}$ and Vinha et al. ${ }^{28}$ This could indicate a comparatively higher storability (shelf life) hence apparent moderate storage value of ASF. ${ }^{29}$ The dry matter content of ASF $(86.91 \pm 0.145 \%)$ compared with that $(94.88-96 \%)$ reported for watermelon rind and seed and indicated high nutrient content in the ASF. ${ }^{1}$ The protein content $(2.64 \pm 0.01 \%)$ compared with the value $(2.19 \pm 0.16 \%)$ reported by Vinha et al. ${ }^{28}$ while the ash content $(3.82 \%)$ compared with the value range $(2.48-3.35 \%)$ for watermelon seed and round orange Carica papaya seed ${ }^{1,30}$ but the oil/ fat content was low compared to that reported previously for avocado pear seed. ${ }^{31}$ In particular, the difference in oil content compared to that obtained by Parameswaran \& Murthi ${ }^{31}$ may be attributed to locationrelated variation. ${ }^{29}$

The crude fiber content $(2.87 \%)$ of the avocado pear seed flour compared with the value range $(2.02-3.10 \%)$ reported for water melon, mango and avocado pear seeds. ${ }^{1,26,32,33}$ Thus, the avocado pear seed could serve as a good dietary fibre source and perhaps fibre health benefits. Fiber improves food bulk, appetite satisfaction and motility through the digestive system and by improving the absorption and re-absorption of cholesterol and bile acids respectively could lower cholesterol level and prevent the formation plaque. ${ }^{34-36}$ The carbohydrate content of ASF was higher than that (25.47\%) reported by Akpabio ${ }^{37}$ for almond seed. This observation, in concert with energy value of ASF (334.01 $\pm 1.05 \%$ ), could be a pointer that avocado pear seed flour could serve as a high carbohydrate source with high energy value. The water absorption capacity $(2.70 \%)$ and the oil absorption capacity $(1.80 \%)$ of ASF in this study were comparable with the values $(3.01 \%)$ and $(1.39 \%)$ respectively reported by Egbuonu et al., ${ }^{38}$ for bitter yam, suggesting that avocado pear seed flour could have flavour retention and mouth feeling properties. ${ }^{1}$

The tannin $(\mathrm{mg} / 100 \mathrm{~g})$ content of ASF (1.14) was quite lower compared with that $(29.21 \mathrm{mg} / 100 \mathrm{~g})$ in Mangifera indica seed kernel. ${ }^{39}$ Also, the cyanogenic glycosides $(\mathrm{mg} / 100 \mathrm{~g})$ content $(1.02 \pm 0.00)$ was lower than the value (21.6) reported by Akpabio et al. ${ }^{37}$ while the phenol $(\mathrm{mg} / 100 \mathrm{~g})$ content $(0.29 \pm 0.01)$ was lower than the value $(6.14 \pm 1.28)$ reported by Arukwe et al., ${ }^{26}$ probably indicated low derivation potential of these antinutrients from ASF. Saponin $(\mathrm{mg} / 100 \mathrm{~g})$ recorded the highest value $(8.10 \pm 0.01)$ among all the determined antinutrients which was higher than the value $(1.55 \pm 0.05)$ reported for watermelon seed by Oseni \& Okoye. ${ }^{40}$ This could be highlighting apparent higher derivation of saponins than the other anti-nutrients from ASF. The alkaloids $(\mathrm{mg} / 100 \mathrm{~g})$ content $(2.14 \pm 0.00)$ of ASF was higher than the value range (0.72-1.23\%) reported for avocado pear and watermelon seeds..$^{26,41}$ but compared with the value $(1.64 \pm 0.10 \%)$ for glycine max reported by Okwu \& Orji. ${ }^{42}$ Alkaloids are plant metabolites with bactericidal activity (Rimando \& Perkinsveazie, ${ }^{43}$ implying that avocado pear seed flour could have antibacterial potentials. Furthermore, the flavonoids $(\mathrm{mg} / 100 \mathrm{~g})$ content compared with the value $(1.90 \pm 0.07)$ reported earlier ${ }^{26}$ and reportedly exhibited antibacterial activity. ${ }^{24}$ Thus we speculated that avocado pear seed flour could have antimicrobial activity.

In apparent support of our speculation, the avocado pear seed extract (ASE) elicited antibacterial activity $(\mathrm{mm})$ against $P$. mirabilis $(23 \pm 0.14)$ which was higher than that against $S$. aureus $(16 \pm 0.04)$ followed by that against $P$. aeruginosa $(15 \pm 0.11)$ though respectively lower than the corresponding activity elicited by the standard antibacterial, Ciprofloxacin. The present result underscored the prospect of ASE as a broad spectrum antifungal following purification warranting further studies. Further to this, ASE elicited higher activity $(18 \pm 0.31 \mathrm{~mm})$ against the fungus, Aspergilus niger on comparison with the standard drug, Ketoconazole $(8 \pm 0.22 \mathrm{~mm})$ indicating apparent overriding potency of ASE over the standard against $A$. niger and perhaps $A$. niger-related diseases. However, while ASE showed activity against Candida albicans that was comparable with that of the standard antifungal, Ketoconazole ( $32 \pm 0.14)$ it had no activity against the pathogenic fungus, Penicillum notatum in contrast to the standard drug $(6 \pm 0.24)$ suggesting that ASE could not serve as a potential broad spectrum antifungal. The spectra of antimicrobial activity shown by ASE could be attributed to the anti-nutrients, notably saponins, alkaloids and flavonoids contained in ASF as reported in this study, and were in consonance with earlier reported antimicrobial activity of avocado pear seeds. ${ }^{12,44,45}$

\section{Conclusion}

Thus, ASF had appreciable nutrient and antinutrient contents with apparently moderate storage value while, out of the tested pathogens, ASE had a broad spectrum antibacterial activity, a selective antifungal activity and an overriding activity against Aspergilus niger. These while highlighting possible diet and drug potentials of ASF and ASE, respectively, provided basis for ethno-medicinal applications of avocado pear seeds hence warranting further studies to harness the possibility of applications in food industries and in medicine. 


\section{Acknowledgments}

None.

\section{Conflict of interest}

Author declares that there is no conflict of interest.

\section{References}

1. Egbuonu ACC. Comparative investigation of the proximate and functional properties of watermelon (Citrullus lanatus) rind and seed. Research Journal of Environmental Toxicology. 2015;9(3):160-167.

2. Egbuonu ACC. Assessment of some antinutrient properties of watermelon (Citrullus lanatus) rind and seed. Research Journal of Environmental Sciences. 2015;9(5):225-232.

3. Egbuonu ACC. Comparative assessment of some mineral, amino acid and vitamin compositions of watermelon (Citrullus lanatus) rind and seed. Asian Journal of Biochemistry. 2015;10(5):230-236.

4. Egbuonu ACC. Comparative investigation of the antibacterial and antifungal potentials of the extracts of watermelon (Citrullus lanatus) rind and seed. European Journal of Medicinal Plants. 2015;9(4):1-7.

5. Ezeanyika LUS, Egbuonu ACC. Impaact of nitric oxide and insulin resistance on the pathophysiology of the metabolic syndrome: Possible role of L-arginine and glutamate. Journal of Medicine and Medical Science. 2011;2(20):657-662.

6. Egbuonu ACC, Ezeanyika LUS. L-arginine exposure improves renal function markers of metabolic syndrome in female rats. American Journal of Biochemistry and Molecular Biology. 2013;3(1):50-60.

7. Adeyemi OO, Okpo SO, Ogunti OO. Analgesic and anti-inflammatory effects of the aqueous extract of leaves of Persea americana Mill (Lauraceae). Fitoterapia. 2002;73(5):375-380.

8. Ojewole JA, Amabeoku GJ. Anticonvulsant effect of Persea america$n a$ Mill. (Lauraceae) (Avocado) leaf aqueous extract in mice. Phytother Res. 2006;20(8):696-700.

9. Anaka ON, Ozolua RI, Okpo SO. Effects of the aqueous seed extract of Persea americana mil (Lauraceae) on the blood pressure of sprague dawley rats. African Journal of Pharmacy and Pharmacology. 2009;3(10):485-490.

10. Egbuonu ACC, Cpara CI, Atasie OC, et al. Vitamins composition and antioxidant properties in normal and monosodium glutamate-compromised rats' serum of avocado pear (Pearsea americana) seed. Open Access Journal of Chemistry. 2017;1(1):19-24.

11. Alhassan AJ, Sule MS, Atiku MK, et al. Effects of aqueous avocado pear (Persea americana) seed extract on alloxan induced diabetes rats. Greener Journal of Medical Sciences. 2012;2(1):005-011.

12. Chia TWR, Dykes GA. Antimicrobial activity of crude epicarp and seed extracts from mature avocado fruit (Persea americana) of three cultivars. Pharm Biol. 2010;48(7):753-756.

13. Egbuonu ACC. Some antinutrient compositions and in-vitro antioxidant properties of milled Carica papaya (pawpaw) peels and seeds. Applied Science Reports. 2017;17(3):75-81.

14. Egbuonu ACC, Osuji CA. Proximate compositions and antibacterial activity of Citrus sinensis (sweet orange) peel and seed extracts. European Journal of Medicinal Plants. 2016;12(3):1-7.

15. Egbuonu ACC, Aguguesi RG, Samuel R, et al. Some physicochemical properties of the petroleum ether-extracted watermelon (Citrullus lanatus) seed oil. Asian Journal of Scientific Research. 2015;8(4):519-525.

16. Okaka JC, Porter NN. Physicochemical and functional properties of cowpea powders processed to reduce bean flavour. Journal of Food Science. 1979;44(4):1235-1240.
17. Harbone JB. Phytochemical methods. London: Chapman and Hall Ltd; 1973. p. $148-189$.

18. Okwu DE, Morah FNI. Isolation and characterization of flavavone glycoside 4, 5, 7-trihydroxyflavanone rhamnoglucose from Garcinia kola seed. Journal of Applied Sciences. 2007;7:306-309.

19. Obadoni BO, Ochuko PO. Phytochemical studies and comparative efficacy of crude extracts of some homeostatic plants in Edo and Delta states of Nigeria. Global Journal of Pure and Applied Sciences. 2011;8(2):303-308.

20. Peason DD. The clinical analysis of food. 7th ed. Edinburgh: Churchill Livingstone; 1976.

21. Egbuonu ACC, Nzewi DC, Egbuonu ONC. Effect of soaking prior to oven-drying on some nutrient and anti-nutrient properties of bitter yam (Dioscorea dumetorum). Journal of Nutrition and Food Science. 2014;4:280

22. Official methods of analysis. 15th ed. Association of Official Analytical Chemistry. Washington DC, USA; 1990:20-26.

23. Onwuka GI. Food analysis and instrumentation (theory and practice). 1 st ed. Naphtali prints Surulere, Lagos, Nigeria; 2005:50-58.

24. Okwu DE, Omodamiro OD. Effects of hexane extract and phytochemical contents of xylopiaethopa and ocimum gratissimum on the uterus of Guinea pig. Bio-Resources. 2005;3(2):40-44.

25. Nostro A, Germano MP, D'Angelo V, et al. Extraction methods and bioautography for evaluation of medicinal plants for antimicrobial activity. Lett Appl Microbiol. 2000;30(5):379-384.

26. Arukwe U, Amadi BA, Duru MKC, et al. Chemical composition of Persea americana leaf, fruit and seed. International Journal Research and Reviews in Applied Sciences. 2012;11(2):346-349.

27. Oluwole S, Yusuf K, Fajana O, et al. Qualitative Studies on Proximate Analysis and Characterization of Oil from Persea americana (Avocado Pear). Journal of Natural Sciences Research. 2013;3(2):68-73.

28. Vinha AF, Moreira J, Barreira VPS. Physicochemical parameters, phytochemical composition and antioxidant activity of the algarvian avocado (Persea americana Mill.). Journal of Agricultural Science. 2013;5(12):100-109.

29. Ejikeme PM, Obasi NL, Egbuonu ACC. Physico-chemical and toxicological studies on Afzella africana seed and oil. African Journal of Biotechnology. 2010;9(13):1959-1963.

30. Nwofia GE, Ojimelukwe P, Eji C. Chemical composition of leaves, fruit pulp and seeds in some Carica papaya (L) morphotypes. International Journal of Medicinal and Aromatic Plants. 2012;2(1):200-206.

31. Parameswaran I, Murthin VK. Comparative study on physico and phytochemical analysis of Persea americana and Actinida deliciosa. International Journal of Scientific Research Publications. 2014;4(5):1-5.

32. Nzikou JM, Kimbonguila A, Matos L, et al. Extraction and characteristics of seed kernel oil from mango (Mangifera indica). Research Journal of Environmental and Earth Sciences. 2010;2(1):31-35.

33. Uzama D, Okolo S, Okoh-Esene RU, et al. A comparative study on the phytochemicals, proximate and mineral contents in the seeds of avocado and African pears. Journal of Pharmaceutical and Biological Sciences. 2015;3(4):198-201.

34. Edem CA, Dosunmu MI, Bassey FI. Determination of proximate composition, ascorbic acid and heavy metal content of African walnut (Tetracarpidium conophorum). Pakistan Journal of Nutrition. 2009;8(3):225-226.

35. Erhirhie EO, Ekene NE. Medicinal values on Citrullus lanatus (watermelon): Pharmacological review. International Journal of Research in Pharmaceutical and Biomedical Sciences. 2013;4:1305-1332. 
36. Okwu DE, Emenike IN. Nutritive value and mineral content of different varieties of citrus fruits. Journal of Food Technology. 2007;7:105-108.

37. Akpabio UD. Evalution of proximate composition, mineral element and anti-nutrients in almond seeds. Advances in Applied Science Research. 2012;3(4):2247-2252.

38. Egbuonu ACC, Nzewi DC, Egbuonu ONC. Functional properties of bitter yam (Dioscorea dumetorum) as influenced by soaking prior to oven-drying. American Journal of Food Technology. 2014;9(2):97-103.

39. Egbuonu ACC, Ekwuribe GA. Pulverized Mangifera indica (mango) seed-kernel modulated serum lipid profile in monosodium glutamate-challenged rats. Journal of Applied Biotechnology. 2017;5(2):72-87.

40. Oseni OA, Okoye VI. Studies of phytochemical and antioxidant properties of the fruit of watermelon (C. lanatus). (Thumb). Journal of Pharmaceutical and Biomedical Sciences. 2013;27(2):508-514.
41. Braide W, Odiong IJ, Oranusi S. Phytochemical and antibacterial properties of the seed of watermelon (Citrullus lanatus). Prime Journal of Microbiology Research. 2012;2(3):99-104.

42. Okwu DE, Orji BO. Phytochemical composition and nutritional quality of Glycine max and Vigna unguiculata (L.) Walp. American Journal of Food Technology. 2007;2:512-520.

43. Rimando AM, Perkins-veazie PM. Determination of citrulline in watermelon rind. J Chromatogr A. 2005;1078(1-2):196-200.

44. Idris S, Ndukwe GI, Gimba CE. Preliminary phytochemical screening and antimicrobial activity of seed extracts of Persea americana (Avocado Pear). Bayero Journal of Pure and Applied Sciences. 2009;2(1):173-176.

45. Leite J, Brito JG, Cordeiro EHS, et al. Chemical composition, toxicity and larvicidal and antifungal activities of Persea americana (avocado) seed extracts. Rev Soc Bras Med Trop. 2009;42(2):110-113. 